\title{
Effect of local application of sympathomimetic drugs to the epididymis on fertility in rats*
}

\author{
W. D. Ratnasooriya $\nmid \ddagger \S$, D. P. Gilmore $\dagger$ and R. M. Wadsworth $\ddagger$ \\ $\dagger$ Institute of Physiology, Glasgow University, Glasgow G12 8QQ, and $\ddagger$ Department of \\ Physiology and Pharmacology, Strathclyde University, Glasgow, G1 1XW, U.K.
}

\begin{abstract}
Summary. Insertion of Silastic rods containing the directly acting sympathomimetic drug, methoxamine, adjacent to the epididymis of rats caused a temporary reduction in fertility with no loss of ability to mate. This effect lasted up to 3 weeks. At the time of the maximal antifertility action (3-7 days after insertion), the number of spermatozoa in the ejaculate fell to almost zero, and there was a reduction in the total number of spermatozoa in the epididymis resulting from a significant drop in the number present in the cauda. Methoxamine also caused immotility and decapitation of the remaining epididymal spermatozoa. The indirectly acting sympathomimetics, tyramine and norephedrine, did not affect fertility. It is postulated that methoxamine acts to induce infertility principally by bringing about a reduction of sperm numbers in the ejaculate. This could have been produced either by a failure of the vas and cauda to contract normally at copulation or because the sperm store in the cauda had fallen below a critical threshold level.
\end{abstract}

\section{Introduction}

Testicular spermatozoa are infertile (Amann \& Griel, 1974; Cooper \& Orgebin-Crist, 1975) and the cumulative weight of evidence indicates that the epididymis is the region within which the spermatozoa acquire their fertilizing potential (Orgebin-Crist, 1967; Cummins, 1976; Cooper \& Orgebin-Crist, 1977). The possibility of interrupting epididymal sperm maturation suggests an attractive method of male contraception. Since spermatogenesis would be unaltered, such a technique would be prompt in action and equally rapidly reversible. Furthermore, it is unlikely that libido would be affected. One possible way to achieve such a goal would be to decrease sperm transit time by using sympathomimetic drugs to induce rhythmic contractions in the epididymis (Hib, 1976; Ratnasooriya, 1978).

This paper reports the effect of fertility of male rats when sympathomimetic drugs were applied locally to the epididymis.

\section{Materials and Methods}

Adult Sprague-Dawley or Wistar rats (males weighing 300-350 g and females weighing 200$250 \mathrm{~g}$ ) were used. The animals were housed under constant environmental conditions with free access to food (Diet 41B: Millers) and water.

* Reprint requests to Dr D. P. Gilmore.

§ Present address: Department of Zoology, Colombo Campus, University of Sri Lanka, Sri Lanka. 


\section{Fertility tests}

Rods containing an appropriate weight of the powdered sympathomimetic drugs together with a known volume of polysiloxane polymer (Silastic 382 Medical Grade Elastomer: Dow Corning Corp., Midland, Michigan, U.S.A.) were prepared exactly as described for collars (Ratnasooriya, Gilmore \& Wadsworth, 1979). The rods were cut into lengths of 15-20 mm with a diameter of $3.5 \mathrm{~mm}$. Each weighed approximately $200 \mathrm{mg}$. Control rods consisting entirely of Silastic were also constructed.

One or two rods were inserted through the tunica vaginalis adjacent to each epididymis of 21 rats lightly anaesthetized with ether. The incision in the tunica vaginalis was sutured and that in the scrotal sac closed with $12 \mathrm{~mm}$ Michel wound clips. The drugs used were methoxamine hydrochloride, tyramine hydrochloride (Wellcome) and norephedrine hydrochloride (Sigma) and the numbers of animals treated in each group are listed in Table 1. The fertility of the treated and control males was tested from Day 3 after the operation by separately pairing each male overnight with a pro-oestrous female.

\section{Sperm distribution in the male tract and ejaculate sperm count}

To investigate the effects of methoxamine hydrochloride on sperm distribution a rod containing $50 \%$ of the drug by weight was placed adjacent to the right epididymis in 6 rats. Within the left tunica vaginalis a control rod was inserted. On Day 3 after the operation the animals were anaesthetized with ether and the excurrent duct from each side was removed and divided into caput, corpus and cauda epididymidis and vas deferens. Each region was homogenized and the number of spermatozoa in it was counted using an improved Neubauer haemocytometer.

Three male rats were each separately paired overnight with one mature pro-oestrous female. Between 09:00 and 10:00 $\mathrm{h}$ the following morning, the females were anaesthetized with ether and the uteri and vaginae were removed. The total number of spermatozoa in the female reproductive tract was counted using an improved Neubauer haemocytometer. Counts were made of repeated ejaculations of each individual male, with not less than 3 days rest between consecutive matings. At least two control counts were made for each rat, before a rod containing $50 \%$ methoxamine hydrochloride was inserted adjacent to each epididymis as described above. Further counts were carried out on Days 3 and 7 after the operation.

\section{Histology and motility of the epididymal spermatozoa}

Following the last mating the 3 male rats used to estimate sperm counts in the female tract were killed and parts of the testis and excurrent duct (cauda, corpus, caput epididymidis and the vas deferens) were removed. The tissue was fixed in Bouin's fluid for subsequent histological examination. Sections were cut at $7 \mu \mathrm{m}$ and stained with haematoxylin and eosin before microscopic examination at $\times 100$ and $\times 400$ magnification.

Spermatozoa were extruded into saline $(9 \mathrm{~g} \mathrm{NaCl} / 1)$ from a portion of the cauda epididymidis immediately before its fixation. The motility of the spermatozoa was scored on a subjective scale of $0-5,0$ being absence of motility and 5 the greatest observed motility.

\section{Sperm counts in the urinary bladder}

A single rod containing $50 \%$ methoxamine hydrochloride was placed adjacent to each epididymis in 4 rats. On Day 4 after operation, the animals were paired individually with a prooestrous female at 17:00-18:00 $\mathrm{h}$. The paired animals were observed until mating occurred. Immediately after copulation the males were killed by an overdose of ether. The urinary bladder was exposed and the entire contents were withdrawn using a $1 \mathrm{ml}$ syringe. A drop of the urine 
was transferred to a microscope slide and examined for any spermatozoa. A vaginal smear was also taken from the female to check for the presence of spermatozoa.

\section{Release rate from $50 \%$ methoxamine hydrochloride rods}

This was calculated by subtracting the final from the initial weight of the rods, after they had been dried at $60-70^{\circ} \mathrm{C}$ until a constant weight had been reached (about 3 days). Release of the methoxamine was such that 3 days after insertion the rods contained $60 \cdot 4-82 \cdot 8 \%(\mathrm{~N}=3)$ of their original content. After 8 days only $1 \cdot 2-5 \cdot 0 \%(N=4)$ of the methoxamine remained.

\section{Statistics}

The significance of differences between the treated and the control groups was assessed using Mann-Whitney or Wilcoxon rank-sum non-parametric tests (Seigel, 1956) taking $P<0.05$ as significant.

\section{Results}

Fertility tests

As shown in Table 1 all 3 control males were fertile and the females with which they were mated had normal numbers of embryos.

Of the 7 rats into which one $50 \%$ methoxamine rod was inserted next to each epididymis, 1 died 2 days after the operation and is excluded from Table 1 . None of the others was fertile at the first mating, but all 6 subsequently showed a progressive return to fertility. However, up to Day 28 , there was a significant reduction in the average number of embryos recorded, compared to those produced by the control group (results combined for Days, 3, 7, 14 and 21: $P<0.05$ ). No abnormalities were detected amongst the litters born from the last two matings.

With the exception of a single mating on Day 3, none of the 3 males into which a single rod containing $25 \%$ methoxamine was inserted was appreciably affected by the treatment. However, the average number of embryos resulting from the matings was less than in the controls. The insertion of rods containing tyramine or norephedrine next to each epididymis had no significant effect on fertility and no gross abnormalities were encountered in the litters derived from tyramine-treated males.

\section{Histological observations and motility of epididymal spermatozoa}

In slides made of tissues taken from the 3 rats killed 8 days after insertion of one $50 \%$ methoxamine rod adjacent to each epididymis, no interference with the spermatogenic process in the testes was apparent. All the stages from spermatogonia to spermatozoa were observed.

The epithelium of the epididymides was normal except in one male in which that of the corpus epididymidis showed disintegration. This was presumably due to some local action of the rod since the cauda and the caput were normal. Numerous spermatozoa were seen in the epididymal lumen and there was an accumulation of cell debris in the proximal caudae. No change was seen in the muscle layers of the vasa deferentia and either no or only very minor damage was caused to the vas epithelium of the treated animals.

The motility score of the cauda spermatozoa, extracted into saline, from these 3 animals was 0 in contrast to control animals which had a sperm motility score of 5 . In addition, large numbers of spermatozoa in the treated animals were decapitate. 
Table 1. The effect (shown by implantation number) of local application of sympathomimetic drugs to the epididymis on the fertility of male rats tested individually with a different female at various times after insertion of the rods

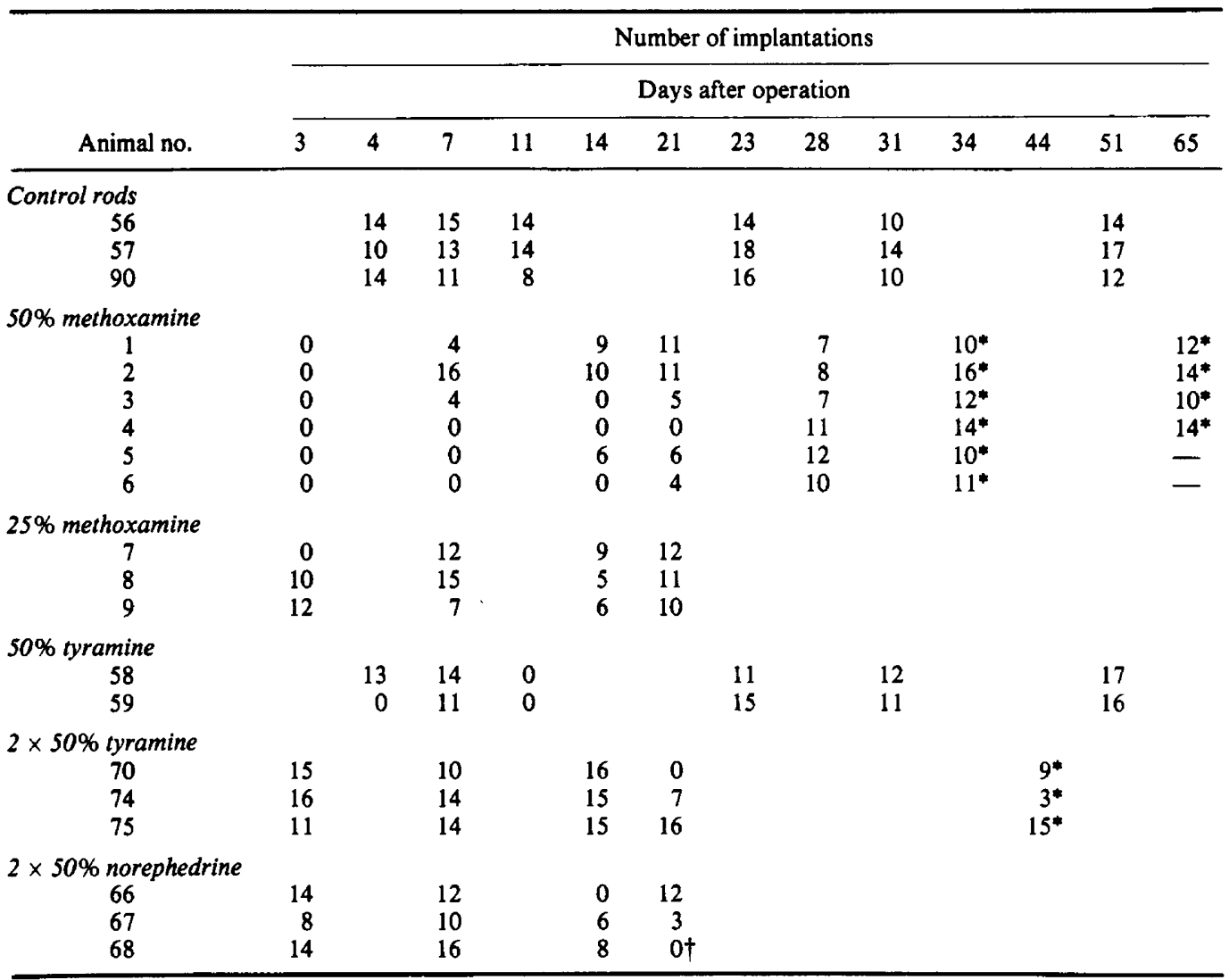

* Females allowed to litter.

+ Adhesions in ovary.

\section{Sperm distribution in the male tract and ejaculate sperm count}

In the 6 rats investigated 3 days after the insertion of a control rod on one side and a $50 \%$ methoxamine-containing rod on the contralateral side the most consistent effects seen were (1) a reduction in sperm numbers in the cauda and the whole epididymis, and (2) the decapitation of a varied proportion of the spermatozoa in the cauda epididymidis and vas deferens (Table 2). A granuloma was observed in the vas deferens of the treated side in one rat. Before removal of the tracts for assessment of sperm content, it was observed that the vas deferens in all 6 animals was contracting rhythmically, but on the treated side only. The ejaculated sperm numbers in the 3 rats investigated ranged from $1 \times 10^{6}$ to $105 \times 10^{6}$ on 2 occasions before the insertion of $50 \%$ methoxamine rods. By 3-7 days after treatment the sperm count of the ejaculate was reduced to very low numbers $\left(<5 \times 10^{4}\right)$ or to zero, and the spermatozoa were mostly decapitate.

\section{Sperm counts in the urinary bladder}

No spermatozoa were seen in the urine in any of the 4 treated males. However, a few spermatozoa were seen in the vaginal smears from 2 of the mated females. Copulatory plugs devoid of spermatozoa were obtained from the other two females. 
Table 2. Effect of methoxamine on the sperm distribution in the genital tract of male rats

\begin{tabular}{|c|c|c|c|c|}
\hline & \multicolumn{4}{|c|}{ Total sperm no. $\left(\times 10^{6}\right)$} \\
\hline & $\begin{array}{l}\text { Control side } \\
\text { (left) }\end{array}$ & $\begin{array}{l}\text { Side with a } 50 \% \\
\text { methoxamine rod } \\
\text { (right) }\end{array}$ & $\%$ decrease & $\begin{array}{c}\% \text { spermatozoa } \\
\text { decapitated } \\
\text { (no. of rats) }\end{array}$ \\
\hline Caput epididymidis & $132 \pm 6$ & $88 \pm 19$ & $33 \pm 15$ & $25(1)$ \\
\hline Corpus epididymidis & $21 \pm 4$ & $19 \pm 4$ & $4 \pm 23$ & - \\
\hline Cauda epididymidis & $175 \pm 9$ & $93 \pm 13^{*}$ & $46 \pm 9 *$ & $95(6)$ \\
\hline Whole epididymis & $328+9$ & $200 \pm 18^{*}$ & $39 \pm 5^{*}$ & - \\
\hline Vas deferens & $35 \pm 20$ & $48 \pm 22$ & $53 \pm 22$ & $92(6)$ \\
\hline
\end{tabular}

- Significantly different from control at $P<0.05$ (Wilcoxon test).

\section{Discussion}

The main result of this study showed that local administration to the epididymis of a directly acting sympathomimetic drug, methoxamine, caused a dramatic reduction in fertility in male rats, but not in their ability to mate. The gradual return to fertility over a 4-week period was presumably due to exhaustion of the drug which had nearly all been released after 8 days. The single death observed probably resulted from the marked cardiovascular stimulation caused by methoxamine. The toxic effects of this drug were most pronounced within the first 2-3 days after administration whereas the antifertility effect lasted at least 3 weeks. Although it is not possible to rule out an effect of methoxamine on spermiogenesis, such an action could not account for the extremely rapid antifertility effect that was observed.

The indirectly acting sympathomimetics, tyramine (Ambache, Dunk, Verney \& Zar, 1972; Wadsworth, 1973) and norephedrine (Ratnasooriya \& Wadsworth, 1979), whose effect is brought about by the release of endogenous noradrenaline from adrenergic neurones, failed to produce any antifertility affect when administered in a similar manner. This would imply that methoxamine induces sterility by its effect upon the non-innervated section of the tract, i.e. caput and proximal corpus epididymidis, rather than upon the cauda and vas deferens which receive a dense adrenergic innervation (El-Badawi \& Schenk, 1962; Norberg, Risley \& Ungerstedt, 1967) and would also be susceptible to the drugs norephedrine and tyramine.

Although the total number of spermatozoa recovered from the female genital tract always showed considerable individual variation (in agreement with the results of Matthew \& Alder, 1977), the number of ejaculated spermatozoa fell dramatically by 3-7 days after the application of methoxamine-containing rods. While this must be the main cause of the observed infertility, the loss of motility and extensive decapitation which also occurred would by themselves be sufficient to produce sterility.

Histological observations demonstrate that the severely oligospermic ejaculates in methoxamine-treated animals cannot be attributed either to obstruction of the epididymis or vas or to spermatogenic arrest. We can also rule out retrograde ejaculation into the bladder since no spermatozoa were detected in the urine after copulation. This leaves two possible explanations for the results obtained. (1) The residual number of spermatozoa in the cauda epididymidis may have been too low for any to enter the ejaculate. The sperm distribution studies showed that the sperm store in the cauda was reduced by about half, but there were still considerable numbers present (about $90 \times 10^{6}$ ). In the hamster $40-45 \%$ of the spermatozoa in the cauda epididymidis remain after repeated ejaculations (Chang \& Sheaffer, 1957), and there may be a similar substantial 'reserve pool' in rats which remains unavailable. (2) The smooth muscle of the cauda epididymidis and vas deferens may have failed to contract at copulation. In theory it seems possible that this could occur as a result of stimulation of presynaptic $\alpha$-receptors (Farnebo \& Malmfors, 1971) or because of desensitization (Wadsworth, 1974). We have no evidence that could allow a choice to be made between possibilities 1 and 2 . 
The reduction in sperm numbers in the cauda epididymidis was not due to redistribution of spermatozoa within the excurrent ducts, since the total number in the whole epididymis was also reduced. It must therefore have been due to enhanced expulsion into the vas deferens or to a reduction in the rate of release from the seminiferous tubules. Since there was no histological evidence of reduced sperm output from the testis, it is likely that the output of spermatozoa into the vas was increased.

Sympathomimetic drugs have been shown to enhance rhythmic contractions in the cauda epididymidis (Da Silva, Gimeno \& Gimeno, 1975; Hib, 1976) and probably also cause contractions in the caput and corpus since these also contain smooth muscle. If such contractions were being induced by methoxamine rods, then this might cause expulsion of sufficient spermatozoa to account for our results. Consistent with this explanation is the observation that tyramine and norephedrine did not affect fertility, since these indirectly acting sympathomimetics would not be expected to cause contraction in the corpus and caput. If increased numbers of spermatozoa were being transferred into the vas, they must subsequently have been lost from there because no accumulation within the vas was found. Such a loss could be accounted for by accelerated transport of spermatozoa through the epididymis and vas, due to rhythmic contractions throughout, eventually resulting in either spontaneous ejaculation (Orbach, 1961; Kihlström, 1966; Ågmo, 1976) or spermatorrhoea (Fernández-Collazo, Videla \& Pereyra, 1971; Vreeburg, Van Andel, Kort \& Westbrock, 1974). Indeed, rhythmic contractions of the vas deferens were observed in our experiments 3 days after the insertion of $50 \%$ methoxamine rods.

The decapitation and loss of motility of the caudal spermatozoa could have resulted from: (1) a direct toxic effect on the spermatozoa themselves; (2) the environment becoming hostile, perhaps by an alteration in the blood supply because methoxamine is a potent vasoconstrictor (Hoffbrand \& Forsyth, 1973); or (3) enhanced transport, leaving insufficient time for the spermatozoa to become fully mature. Of these three possibilities (2) seems the most likely since decapitation was always first observed in the cauda epididymidis.

Our intention was to apply drugs only to the epididymis, but diffusion of drug to the testis, vas and their blood and nerve supplies may have occurred and we have therefore considered all of these tissues as possible sites of action. The effects observed were similar to those produced by sympathomimetic drugs applied directly to the vas deferens in the form of Silastic collars (Ratnasooriya et al., 1979). However, while the possibility exists that the collars might themselves have obstructed the passage of spermatozoa along the vas, there was no evidence that the rods had this effect. Furthermore, as decapitated spermatozoa were produced only by animals which had received rods this method of application appears to supply the greatest concentration of drug to the epididymis.

We thank the late Dr Mary Hay and Dr H. Dott, Animal Research Station, Cambridge, for assistance in the interpretation of histological material; Mr D. W. Richardson, Reproductive Biology Unit, Edinburgh, for demonstrating his technique for measuring the sperm distribution in the epididymis; Mr Frank Fleming and his staff of the Glasgow University Animal Unit for all the assistance they provided; and Mrs R. Deas for her excellent secretarial work. The Scottish Hospital Endowments Research Trust provided financial support and The Wellcome Research Laboratories donated a generous supply of methoxamine. W.D.R. was supported by an open scholarship from the Association of Commonwealth Universities.

\section{References}

Agmo, A. (1976) The number of spermatozoa in the spontaneous ejaculates of rats. J. Reprod. Fert. 48, $405-407$.
Amann, R.P. \& Griel, L.C. (1974) Fertility of bovine spermatozoa from rete testis, cauda epididymides and ejaculated semen. J. Dairy Sci. 57, 212-219. 
Ambache, N., Dunk, L.P., Verney, J. \& Zar, M.A. (1972) Inhibition of postganglionic motor transmission in vas deferens by indirectly acting sympathomimetic drugs. J. Physiol., Lond. 227, 433456.

Chang, M.C. \& Sheaffer, D. (1957) Number of spermatozoa ejaculated at copulation, transported into the female tract, and present in the male tract of the golden hamster. J. Hered. 48, 107-109.

Cooper, T.G. \& Orgebin-Crist, M.C. (1975) The effect of epididymal and testicular fluids on the fertilizing capacity of testicular and epididymal spermatozoa. Andrologia 7, 85-93.

Cooper, T.G. \& Orgebin-Crist, M.C. (1977) Effect of ageing on the fertilizing capacity of testicular spermatozoa from the rabbit. Biol. Reprod. 16, 258-266.

Cummins, J.M. (1976) Effects of epididymal occlusion on sperm maturation in the hamster. J. exp. Zool. 197, 187-190.

Da Silva, M.C., Gimeno, M.F. \& Gimeno, A.L. (1975) Physiologic and pharmacologic studies on the motility of isolated guinea-pig cauda epididymides. Fert. Steril. 26, 1250-1256.

El-Badawi, A. \& Schenk, E.A. (1962) The distribution of cholinergic and adrenergic nerves in the mammalian epididymis. A comparative histochemical study. $A m$. J. Anat. 121, 1-14.

Farnebo, L. \& Malmfors, T. (1971) [ $\left.{ }^{3} \mathrm{H}\right]$ noradrenaline release and mechanical response in the field stimulated mouse vas deferens. Acta physiol. scand. Suppl. 371, $1-18$.

Fernández-Collazo, E., Videla, E. \& Pereyra, J.C. (1971) Elimination of spermatozoa in the urine of isolated male rats. J. Reprod. Fert. 27, 145-147.

Hib, J. (1976) Effects of autonomic drugs on epididymal contractions. Fert. Steril. 27, 951-956.

Hoftbrand, B.I. \& Forsyth, R.P. (1973) Regional blood flow changes during norepinephrine, tyramine and methoxamine infusions in the anaesthetized Rhesus monkey. J. Pharmac. exp. Ther. 184, 656-661.
Kihlström, J.E. (1966) Diurnal variations in the spontaneous ejaculations of the male albino rat. Nature, Lond. 209, 513-514.

Matthew, M. \& Alder, N.T. (1977) Facilitative and inhibitory influences of reproductive behaviour on sperm transport of rats. J. comp. Physiol. Psychol. 91, 727-741.

Norberg, K.H., Risley, P.L. \& Ungerstedt, V. (1967) Adrenergic innervation of the male reproductive ducts in some mammals. II. Effects of vasectomy and castration. Experientia 23, 392-394.

Orbach, J. (1961) Spontaneous ejaculations in rat. Science, N.Y. 134, 1072-1073.

Orgebin-Crist, M.C. (1967) Sperm maturation in rabbit epididymis. Nature, Lond. 216, 816-818.

Ratnasooriya, W.D. (1978) Effects of sympathomimetic drugs on the contractility of the vas deferens of male rats and rabbits. Ph.D. thesis, University of Strathclyde.

Ratnasooriya, W.D. \& Wadsworth, R.M. (1979) The effect of 6-hydroxydopamine on contractions produced by sympathomimetic amines on the human isolated vas deferens. J. Pharm. Pharmac. 31, 348350.

Ratnasooriya, W.D., Gilmore, D.P. \& Wadsworth, R.M. (1979) Antifertility effect of sympathomimetic drugs on male rats when applied locally to the vas deferens. J. Reprod. Fert. 56, 643-651.

Siegel, S. (1956) Non-parametric Statistics for the Behavioral Sciences. McGraw-Hill, New York.

Vreeburg, J.T.H., Van Andel, M.V., Kort, W.J. \& Westbrock, D.L. (1974) The effect of hemicastration on daily sperm output in the rat as measured by a new method. J. Reprod. Fert. 41, 355-359.

Wadsworth, R.M. (1973) Abolition of neurally evoked motor responses of the vas deferens by 6-hydroxydopamine. Eur. J. Pharmac. 21, 386-387.

Wadsworth, R.M. (1974) Excitatory and inhibitory effects of noradrenaline on the isolated guinea pig vas deferens. Clin exp. Pharmac. Physiol. 1, 135-145. 